\begin{tabular}{|c|c|c|}
\hline & Int.J.Curr.Microbiol.App.Sci (2021) 10(09): 368-374 & \\
\hline EXCELLENT & $\begin{array}{l}\text { International Journal of Current Microbiology and Applied Sciences } \\
\text { ISSN: 2319-7706 Volume } 10 \text { Number } 09 \text { (2021) } \\
\text { Journal homepage: http://www.ijcmas.com }\end{array}$ & 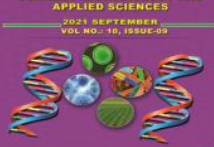 \\
\hline $\begin{array}{l}\text { EXCELLENT } \\
\text { PUBLISHERS }\end{array}$ & & \\
\hline
\end{tabular}

\title{
Sensitivity Analysis of CERES-Wheat Model under Hisar Conditions
}

\author{
M. K. Nayak ${ }^{1}$, Raj Singh ${ }^{1}$, Anil Kumar ${ }^{1}$, Surender Singh ${ }^{1}$ and Deepak Patil ${ }^{2}$ \\ ${ }^{1}$ Department of Agricultural Meteorology, College of Agriculture, CCS Haryana \\ Agricultural University, Hisar, Haryana-125004, India \\ ${ }^{2}$ Anand Agricultural University, Anand, Gujarat- 388110, India \\ *Corresponding author
}

Keywords

Growing

environments,

irrigation levels,

wheat crop,

sensitivity analysis,

DSSAT model

Article Info

Accepted:

15 August 2021

Available Online:

10 September 2021

\section{A B S T R A C T}

The field experiment was conducted at Research Farm, Dept of Agricultural Meteorology, CCS HAU, Hisar (Lat.: $29^{0} 10^{\prime} \mathrm{N}, \log _{\text {.: }} 75^{0} 36^{\prime}$ E \& $215.2 \mathrm{~m}$ above $\mathrm{msl}$ ), Haryana, India during the rabi season of 2014-15 and 2015-16. Experimental designed laid out with strip plot, as main plot treatment: four growing environments i.e. $\mathrm{D}_{1}: 5^{\text {th }}$ Nov., $\mathrm{D}_{2}: 20^{\text {th }}$ Nov., $\mathrm{D}_{3}$ : $5^{\text {th }}$ Dec. and $\mathrm{D}_{4}$ : $20^{\text {th }}$ Dec. and sub-plot treatment: four irrigation regimes, it applied at different phenophases ( $\mathrm{I}_{1}-\mathrm{CRI}, \mathrm{I}_{2}-\mathrm{CRI}$ and heading, $\mathrm{I}_{3}-\mathrm{CRI}+$ jointing and milking, $\mathrm{I}_{4}-\mathrm{CRI}+$ jointing + anthesis and dough stage). Crop growth and yield data of 2014-15 were used for calibration of DSSAT model and cultivar coefficients for WH1105 based on the observed crop characteristics. Genetic coefficient parameters are in the ranges obtained by the few other studies conducted on wheat with the exception of parameters G1, G2, and G3, related to grain growth. Sensitivity of simulated grain yield to down scaled sunshine hours, solar radiation -0.5 to -2.5 hours and $1^{\circ} \mathrm{C}$ to $-5 \mathrm{MJ}^{-2}$ day $^{-1}$ showed a gradual decrease in grain yield, respectively.

\section{Introduction}

The crop simulation models are recent tools that can facilitate the identification of production constraints and assist in agrotechnology transfer. They are being widely used as management tool to evaluate the effects of climate, soil, hydrologic and agronomic factors on crop yield and variability. Studies on phenology and yield simulation of wheat have been reported by Aggarwal and Kalra (1994) using WTGROS and Hundal and Kaur (1997) using CERESWheat model. The simulation technology possess the capability to perform in any environment once the genetics co-efficient of a particular cultivar are developed or the model is validated as genotypic constitution, 
edaphic and atmospheric factors. The CERESwheat model simulates the effect of inputs, such as weather, soil and major soil characteristics and crop management on wheat growth, development and yield. Evaluation of this model under Hisar condition may give a prospect to rearrange wheat production management practices accordingly to mitigate future climate change effect.

Cropping system models are process based computer simulation models that simulate the daily water, nutrient, and plant growth processes occurring within agricultural cropping systems throughout the growing season. These models can be used to simulate the collective effects of meteorological conditions, soil properties, cultivar characteristics, and management practices on crop growth, development, water use and yields (Jones et al., 2003). The CERESWheat model (Godwin et al., 1989, Ritchie et al., 1988; Singh et al., 1991) is a well-known wheat simulation model. In current climatic change scenario extreme weather events like unpredictable rains during winter season, extreme temperatures, frost and hail storms etc. affect growth and productivity of wheat crop.

\section{Materials and Methods}

The field experiment was conducted Research Farm Dept of Agricultural Meteorology, CCS Haryana Agricultural University, Hisar (Lat.: $29^{0} 10^{\prime} \mathrm{N}$, Log.: $75^{\circ} 36^{\prime}$ E \& $215.2 \mathrm{~m}$ above $\mathrm{msl})$, Haryana, India during the rabi season in the year 2014-15 and 2015-16. Experiment was laid out with four growing environments $\left(\mathrm{D}_{1}: 5^{\text {th }}\right.$ Nov., $\mathrm{D}_{2}: 20^{\text {th }}$ Nov., $\mathrm{D}_{3}: 5^{\text {th }}$ Dec. and $\mathrm{D}_{4}: 20^{\text {th }}$ Dec.) along with four irrigation levels was applied at different phenophases $\left(\mathrm{I}_{1}-\mathrm{CRI}\right.$, $\mathrm{I}_{2}$ - CRI and heading, $\mathrm{I}_{3}-\mathrm{CRI}+$ jointing and milking, $\mathrm{I}_{4}-\mathrm{CRI}+$ jointing + anthesis and dough stage) under strip plot design with four replication at semi arid climatic condition of
Hisar zone. The number of days to attain various phenophases was determined from randomly selected five plants in all the plots visually by the number of days taken from the sowing date to attain respective phenophases up to maturity.

\section{Results and Discussion}

\section{Sensitivity analysis of CERES- wheat model to various weather parameters}

As much as $80 \%$ of variability of agricultural production is sensitive mainly to variability in weather conditions. These include bright sunshine hours, solar radiation, maximum and minimum air temperature and variation in carbon dioxide concentration levels. Therefore, the results produced by the models during the present investigation can be used to make appropriate management decisions and to provide farmers and farming community with alternative options for their farming systems. In most climate change applications, long term historical data is used as input for the models. But, in the present investigation, the simplest approach by assuming a fixed climate change by modifying the data with a constant number, such as an increase considered as super optimum and decrease as sub optimum for bright sunshine hours, solar radiation, maximum and minimum temperature elevated over actual i.e. $\pm 1,2,3$, 4 , and $5^{\circ} \mathrm{C}$ and carbon dioxide concentration from 450, 500 and $550 \mathrm{ppm}$ was applied to daily weather data. The crop simulation models were performed to determine the sensitivity of seed yield levels in the varying weather variables and futuristic climate change impact for these modified inputs for wheat crop production. The model simulated results with altered weather was compared with base yield $\left(6505 \mathrm{~kg} \mathrm{ha}^{-1}\right)$. The base yield was simulated by model having normal weather data and normal packages and practices. 


\section{Effect of bright sunshine hours (hrs)}

The results of varying bright sunshine hours and its effects on wheat grain yield as simulated by CERES-Wheat model for optimal situations is presented in Table 1.

Results showed that with increase from 1.5 to $2.5 \mathrm{hrs}$ bright sunshine hours percentage yield increased from 11.5 to 23.5 in comparison with base yield (Table 3). Highest yield increment was observed at $2.5 \mathrm{hrs}(8034 \mathrm{~kg}$ $\left.\mathrm{ha}^{-1}\right)$. In case of gradual reduction in bright sunshine hrs gradual decrease in yield in terms of per cent change from base yield was noted as -1.9 to -16.5 for reduction in bright sunshine by -0.5 to $-2.5 \mathrm{hrs}$ respectively. Thus a scrutiny of the overall response to varying bright sunshine to grain yield of wheat showed that the model was quite sensitive to bright sunshine. Sensitivity of CERES-wheat model simulated in yield to incremental units of BSS showed a gradual increased in yield and down scaled BSS decreased the yield due to reduction in BSS (Table 1). Such behavior of the model was mainly due to reduction in anthesis and photosynthesis with decrease in BSS and vice versa.

\section{Effect of solar radiation}

The results of varying solar radiation and its effects on wheat grain yield as simulated by CERES-Wheat model for in Table 2.

Results showed that with increase from 3 to 5 $\mathrm{MJ} \mathrm{m}^{-2}$ day $^{-1}$ solar radiation, percentage yield increased from 5 to 8 in comparison with base yield (Table 4). Highest yield increment was observed at $4 \mathrm{MJ} \mathrm{m}^{-2}$ day $^{-1}\left(7351 \mathrm{~kg} \mathrm{ha}^{-1}\right)$. In case of gradual reduction in solar radiation, gradual decrease in yield in terms of per cent change from base yield was noted as -37 to 87 for reduction in solar radiation by -1 to -5
MJ $\mathrm{m}^{-2}$ day $^{-1}$, respectively. Photoperiod sensitivity, expressed as the increase in number of leaves produced per an increase of hour of photoperiod over 12 hour ranged from 0.3 to 1.5 leaves $\mathrm{h}^{-1}$ in maize (Birch et al., 1998). Thus, a scrutiny of the overall response of varying radiation to grain yield of wheat showed that the model was highly sensitive to radiation than it was to temperature. Results showed that with increase solar radiation percentage yield increased from 5 to 8 per cent in comparison with base yield (Table 2). In case of gradual reduction in solar radiation gradual decrease in yield in terms of per cent change from base yield was noted.

\section{Effect of maximum temperature}

The effects of maximum temperature on simulated grain yield of wheat under optimal condition and the comparison of this simulated grain yield with base yield and its per cent change from base yield are presented in Table 3.

Sensitivity of CERES-Wheat model simulated grain yield to incremental units of maximum temperature showed a gradual decrease in yield ranging from 4488 to $2797 \mathrm{~kg} \mathrm{ha}^{-1}$ (Table 5). The down scaled maximum temperature increased the yield by 3 and 5 per cent at 4 and $5^{\circ} \mathrm{C}$ reduction in maximum temperature, respectively. The reduction in temperature from -1 to $-3^{\circ} \mathrm{C}$ also revealed an increasing yield. Sensitivity of CERES-model simulated grain yield to incremental units of maximum temperature showed a gradual decrease in yield and down scaled maximum temperature increased the yield (Table 3 ).

Such a behaviour of the model was mainly due to reduction in duration of anthesis and grain filling with rise in maximum temperature and vice versa (Aggarwal and Kalra, 1994a). 
Table.1 Sensitivity of CERES model to bright sunshine hours (hrs)

\begin{tabular}{|c|c|c|}
\hline $\begin{array}{c}\text { Bright sunshine hours } \\
(\mathbf{h r s})\end{array}$ & $\begin{array}{c}\text { Simulated grain yield } \\
\left(\mathbf{k g ~ h a}^{-\mathbf{1}}\right)\end{array}$ & \% change from baseline yield \\
\hline $\mathbf{2 . 5}$ & 8034 & 23.5 \\
\hline $\mathbf{2 . 0}$ & 7429 & 14.2 \\
\hline $\mathbf{1 . 5}$ & 7253 & 11.5 \\
\hline $\mathbf{1 . 0}$ & 6928 & 6.5 \\
\hline $\mathbf{0 . 5}$ & 6655 & 2.3 \\
\hline $\mathbf{0 . 0}$ & 6505 & 0.0 \\
\hline $\mathbf{- 0 . 5}$ & 6381 & -1.9 \\
\hline $\mathbf{- 1 . 0}$ & 6225 & -4.3 \\
\hline $\mathbf{- 1 . 5}$ & 5907 & -9.2 \\
\hline $\mathbf{- 2 . 0}$ & 5802 & -10.8 \\
\hline $\mathbf{- 2 . 5}$ & 5432 & -16.5 \\
\hline
\end{tabular}

Table.2 Sensitivity of CERES model to solar radiation $\left(\mathrm{MJ}^{-2} \mathrm{day}^{-1}\right)$

\begin{tabular}{|c|c|c|}
\hline $\begin{array}{c}\text { Solar radiation } \\
\left(\mathbf{M J ~ m}^{-\mathbf{2}} \mathbf{~ d a y ~}^{-\mathbf{1}}\right)\end{array}$ & $\begin{array}{c}\text { Simulated grain yield } \\
\left(\mathbf{k g ~ h a}^{-\mathbf{1}} \mathbf{)}\right.\end{array}$ & $\begin{array}{c}\text { \% change from baseline } \\
\text { yield }\end{array}$ \\
\hline $\mathbf{1}$ & 5659 & -13.0 \\
\hline $\mathbf{2}$ & 6466 & -0.6 \\
\hline $\mathbf{3}$ & 6830 & 5.0 \\
\hline $\mathbf{4}$ & 7351 & 13.0 \\
\hline $\mathbf{5}$ & 7025 & 8.0 \\
\hline $\mathbf{- 1}$ & 4098 & -37.0 \\
\hline $\mathbf{- 2}$ & 3513 & -46.0 \\
\hline $\mathbf{- 3}$ & 1756 & -73.0 \\
\hline $\mathbf{- 4}$ & 1431 & -78.0 \\
\hline $\mathbf{- 5}$ & 846 & -87.0 \\
\hline
\end{tabular}

Table.3 Sensitivity of CERES model to maximum temperature $\left({ }^{0} \mathrm{C}\right)$

\begin{tabular}{|c|c|c|}
\hline Tmax $\left(\mathbf{(}^{\mathbf{C})}\right.$ & $\begin{array}{c}\text { Simulated grain yield } \\
\left(\mathbf{k g ~ h}^{\mathbf{- 1}} \mathbf{)}\right.\end{array}$ & \% change from baseline yield \\
\hline $\mathbf{1}$ & 4488 & -31.0 \\
\hline $\mathbf{2}$ & 4163 & -36.0 \\
\hline $\mathbf{3}$ & 3578 & -45.0 \\
\hline $\mathbf{4}$ & 3253 & -50.0 \\
\hline $\mathbf{5}$ & 2797 & -57.0 \\
\hline $\mathbf{- 1}$ & 5464 & -16.0 \\
\hline $\mathbf{- 2}$ & 5724 & -12.0 \\
\hline $\mathbf{- 3}$ & 6180 & -5.0 \\
\hline $\mathbf{- 4}$ & 6700 & 3.0 \\
\hline $\mathbf{- 5}$ & 6830 & 5.0 \\
\hline
\end{tabular}


Table.4 Sensitivity of CERES model to minimum temperature $\left({ }^{0} \mathrm{C}\right)$

\begin{tabular}{|c|c|c|}
\hline Tmin $\left({ }^{\mathbf{0}} \mathbf{C}\right)$ & $\begin{array}{c}\text { Simulated grain yield } \\
\mathbf{( k g ~ h a}^{-\mathbf{1}} \mathbf{)}\end{array}$ & \% change from baseline yield \\
\hline $\mathbf{5}$ & 4391 & -32.5 \\
\hline $\mathbf{4}$ & 5237 & -19.5 \\
\hline $\mathbf{3}$ & 5367 & -17.5 \\
\hline $\mathbf{2}$ & 5822 & -10.5 \\
\hline $\mathbf{1}$ & 6199 & -4.7 \\
\hline $\mathbf{0}$ & 6505 & 0.0 \\
\hline $\mathbf{- 1}$ & 6668 & 2.5 \\
\hline $\mathbf{- 2}$ & 7129 & 9.6 \\
\hline $\mathbf{- 3}$ & 7201 & 10.7 \\
\hline $\mathbf{- 4}$ & 7565 & 16.3 \\
\hline $\mathbf{- 5}$ & 8177 & 25.7 \\
\hline
\end{tabular}

Table.5 Sensitivity of CERES model to elevated $\mathrm{CO}_{2}(\mathrm{ppm})$

\begin{tabular}{|c|c|c|}
\hline Elevated $\mathbf{C O}_{\mathbf{2}}(\mathbf{p p m})$ & Simulated grain yield $\left(\mathbf{k g ~ h a}^{\mathbf{- 1}}\right)$ & \% change from baseline yield \\
\hline $\mathbf{4 5 0}$ & 6973 & 7.2 \\
\hline $\mathbf{5 0 0}$ & 7318 & 12.5 \\
\hline $\mathbf{5 5 0}$ & 7852 & 20.7 \\
\hline
\end{tabular}

\section{Effect of minimum temperature}

The effects of minimum temperature on simulated grain yield of wheat under optimal condition and the comparison of this simulated grain yield with base yield and its per cent change from base yield are presented in Table 4.

The sensitivity of CERES model simulated seed yield to super optimum condition with incremental units of minimum temperature 1 to $5{ }^{0} \mathrm{C}$ showed a gradual decrease in yield levels. The decrease in grain yield varied according to the increase in the minimum temperature. The decrease was lowest for $1{ }^{\circ} \mathrm{C}$ $(-4.7 \%)$ and was highest at $5{ }^{0} \mathrm{C}(-32.5 \%)$. However, the grain yield increased with decrease in the minimum temperature upto -5 ${ }^{0} \mathrm{C}$. The yield increased by $2.5 \%$ to $25.7 \%$ from -1 to $-5{ }^{0} \mathrm{C}$, respectively. Sensitivity of CERES- wheat model simulated grain yield to incremental units of minimum temperature showed a gradual decrease in yield and down scaled of minimum temperature increased the yield (Table 4). Such type of behaviour of the model with minimum temperature was mainly due to reduction in duration of phenophases and increased water requirement due to increased respiration rate and vice versa.

\section{Effect of elevated carbon dioxide}

The effect of elevated carbon dioxide on simulated grain yield of wheat under optimal condition in relation to base yield have been shown in Table. 7.

The sensitivity of CERES model simulated seed yield to optimum condition elevated $\mathrm{CO}_{2}$ 450,500 and $550 \mathrm{ppm}$ showed a gradual increase in yield levels. The increase in seed yield varied according to the elevated $\mathrm{CO}_{2}$. The increase was lowest at $450 \mathrm{ppm}$ (7.2\%) 
and was highest at $550 \mathrm{ppm}(20.7 \%)$. This clearly showed that doubled concentration of $\mathrm{CO}_{2}$ had a significant and positive impact on the grain yield of wheat. This study also revealed that doubling the $\mathrm{CO}_{2}$ concentration caused an increase in yield by $40 \%$ due to higher assimilation rates as observed in case of results simulated by SUCROS87 model for wheat. Jamieson et al., (2000) tested the performance of the models AFRCWHEAT2, FASSET and Sirius by elevated $\mathrm{CO}_{2}$ and showed that the effects of elevated $\mathrm{CO}_{2}$ on grain yields of wheat were expressed through the effects on light use efficiency (LUE).

Grain yield, straw yield, and harvest index were satisfactorily simulated by the CERESwheat model both under optimal and sub optimal conditions under varying environmental conditions. This clearly showed the robustness of the CERES- wheat model. The CERES- wheat model overestimated the days to anthesis, leaf stem weight at anthesis and physiological maturity. The CERESwheat model underestimated leaf area index. This result suggested that functional form of the leaf area index simulation sub route needed to be revised as it has a direct relevance to biomass production.

\section{References}

Aggarwal, P. K. and Kalra, N. (1994). Analyzing the limitations set by climatic factors, genotype and water and nitrogen availability on productivity of wheat II. Climatically potential yields and management strategies. Field Crops Research, 38 : 93-103.

Aggarwal, P. K. and Kalra, N. (eds.) (1994a). Simulating the effect of climatic factors, genotypes and management of productivity of wheat in India. Division of Environmental Science, IARI, New Delhi, India. pp 156.
Bannayan, M., Crout, N. M. J. and Hoogenboom, G. (2003). Application of the CERES Wheat model for within-season prediction of winter wheat yield in the United Kingdom. Agronomy Journal, 95 (1): 114-125.

Barnes, E. M., Pinter, Jr. P. J., Kimball, B. A., Hunsaker, D. J., Wall, G. W. and LaMorte, R. L. (2000). Precision irrigation management using modeling and remote sensing approaches. In: Evans R G, Benham B L, Trooien T. (Eds.). The $4^{\text {th }}$ Decennial National Irrigation Symposium. ASAE, Phoenix, AZ. pp 332-337.

Dettori, M., Cesaraccio, C., Motroni, A., Spano, D. and Duce, P. (2011). Using CERES Wheat to simulate durum wheat production and phenology in Southern Sardnia, Italy. Field Crop Research, 120:179-188.

Gabrielle, B., Roche, R., Angas, P., CanteroMartinez, C., Cosentino, L., Mantineo, M., Langensiepen, M., Hénault, C., Laville, P., Nicoullaud, B. \& Gosse, G. (2002) A priori parameterisation of the CERES soil-crop models and tests against several European data sets. Agronomie, 22, 119-132.

Godwin, D. C., Ritchie, J. T., Singh, U. and Hunt, L. (1989). A User's Guide to CERES-Wheat $\mathrm{v}$ 2.1. International Fertilizer Development Centre, Muscle Shoals, A L.

Hoogenboom, G., Jones, J. W., Wilkens, P. W., Porter, C. H., Boote, K. J., Hunt, L. A., Singh, U., Lizaso, J. L., White, J. W., Uryasev, O., Royce, F.S., Ogoshi, R., Gijsman, A. J., Tsuji, G. Y. and Koo, J. (2012). Decision Support System for Agrotechnology Transfer (DSSAT) Version 4.5. University of Hawaii, Honolulu, Hawaii.

Hundal, S. S. and Kaur, P. (1997). Application of the CERES-Wheat model to 
predictions in the irrigated plains of the Indian Punjab. The Journal of Agricultural Science, 129 (1): 13-18

Hunt, L. A., Pararajasingham, S., Jones, J. W., Hoogenboom, G., Imamura, D. T. and Ogoshi, R. M. (1993). Gentale : Software to facilitate the use of crop models to analyse field experiment. Agronomy Journal, 85 : 1090-94.

Iglesias, A., Rosenzweig, C. and Pereira, D. (2000). Agricultural impacts of climate change in Spain: developing tools for a spatial analysis. Global Environmental Change, 10 (1): 69-80.

Jamieson, P. D., Berntsen, J., Ewert, F., Kimball, B. A., Olsen, J. E., Pinter, P. J. Jr., Porter, J. R. and Semenov, M. A. (2000). Modeling CO2 effects on wheat with varying nitrogen supplies. Ecosystem and Environment, 82(1-3): 27-37.

Jamieson, P. D., Porter, J. R., Goudriaan, J., Ritchie, J. T., van Keulen, H. and Stol, W. (1998). A comparison of the models AFRCWHEAT2, CERESWheat, Sirius, SUCROS2 and SWHEAT with measurements from wheat grown under drought. Field Crops Research, 55 (1-2): 23-44.

Jones, J. W., Hoogenboom, G., Porter, C. H., Boote, K. J., Batchelor, W. D., Hunt, L. A., Wilkens, P. W., Singh, U., Gijsman, A. J. and Ritchie, J. T. (2003). The DSSAT cropping system model. European Journal of Agronomy, 18: 235-265.

Lobell, D. B. and Ortiz-Monasterio, J. I.
(2006). Evaluating strategies for improved water use in spring wheat with CERES. Agricultural Water Management, 84 (3):249-258.

Ouda, S. A., El-Marsafawy, S. M., El-Kholy, M. A. and Gaballah, M. S. (2005). Simulating the effect of water stress and different sowing dates on wheat production in South Delta. Journal of Applied Sciences Research, 1(3): 268276.

Overman, A. R. and Blue, W. G. (1990). Estimating yields and forage $\mathrm{N}$ for bahia grass production in Florida. Soil Crop Science Society of Florida Production, 49, 113-117.

Overman, A. R., Wilkinson, S. R. and Evers, G. W. (1992). Yield response of Bermudagrass and Bahiagrass to applied nitrogen and overseed clover. Agronomy Journal, 84, 998-1001.

Ritchie, J. T., Godwin, D. C. and Otter-Nacke, S. (1988). CERES-Wheat- A simulation Model of Wheat Growth and Development. Texas $A$ \& $M$ University Press, College Station.

Singh, U., Ritchie, J. T. and Thornton, P. K. (1991). CERES-Cereal model for wheat, maize, sorghum, barley, and pearl millet, Agronomy Abstracts. ASA, Madison, WI. p 78.

Timsina, J. and Humphreys, E. (2006). Performance of CERES-Rice and CERES-Wheat models in rice-wheat systems: a review. Agricultural Systems, 90: 5-31.

\section{How to cite this article:}

Nayak, M. K., Raj Singh, Anil Kumar, Surender Singh and Deepak Patil. 2021. Sensitivity Analysis of CERES-Wheat Model under Hisar Conditions. Int.J.Curr.Microbiol.App.Sci. 10(09): 368-374. doi: https://doi.org/10.20546/ijcmas.2021.1009.042 